\title{
100 years of teaching and researching in Dermatology
}

\author{
João Avancini, Paula Silva Ferreira, Cyro Festa Neto, José Antonio Sanches
}

T

he history of the Department of Dermatology begins in 1916, February 26th, when Prof. Adolpho Carlos Lindenberg performed the first dermatology lesson for the recently created Faculty of Medicine and Surgery of Sao Paulo, future Faculty of Medicine of the University of Sao Paulo (FMUSP). Prof. Lindenberg graduated in the Faculty of Medicine of Rio de Janeiro and specialized in dermatology with European reputed professors, like Prof. Lesser, Riehl, Brocq and Sabouraud, and was one of the pioneers in Brazilian dermatology, having created in 1907 the Skin's Disease Department in the hospital Santa Casa de Misericórdia de São Paulo. He focused not only on teaching dermatology, but also on clinical practice and researches, especially studying leishmaniasis, fungal infections and pemphigus foliaceous.

The first league held by students of the faculty, the traditional "Liga de Combate à Sífilis" (Syphilis' League) was created in 1920 by Prof. João de Aguiar Pupo, focused in the treatment of syphilis and remains until nowadays as one of the most important academic leagues in Brazil.

In 1929 Prof. Lindenberg retired, and Prof. João de Aguiar Pupo was nominated the new chairman. At that time, dermatology lessons were taken at the outpatient service "Ambulatório Conde Lara" and in the inpatient service of the Santa Casa de Misericórdia de São Paulo. Prof. Pupo developed important studies regarding leprosy, leishmaniasis and paracoccidioidomycosis, and described the oral mucous lesions on paracoccidioidomycosis, known as moriform stomatitis of Aguiar-Pupo.

In 1935, one year after the foundation of the University of Sao Paulo, Prof. Pupo created the $23^{\text {rd }}$ Clinic-Chair of Syphilography and, in 1945, the Division of Dermatology was transferred to the recently created Hospital das Clínicas (Clinics Hospital, HC-FMUSP).

Prof. Pupo was not only the chairman but also nominated for three times the principle of the Faculty of Medicine. In 1960, after his retirement, Prof. Sebastião de Almeida Prado Sampaio was nominated the new chairman of the department. With his international experience at the Mayo Foundation for Medical Education and Research and his visionary leadership, Prof. Sampaio was responsible for the transition between the traditional morphologic dermatology to a modern approach, concerning the use of basic sciences in the understanding of pathophysiology, diagnosis and treatment of skin diseases. His scientific production was remarkable, having published more than 120 articles in important subjects, such as pemphigus foliaceous, antifungal treatments, lupus erythematous,

Departament of Dermatology at "Faculdade de Medicina da Universidade de São Paulo (FMUSP)".

Mailing address: Departamento de Departamologia da FMUSP. Av. Dr. Enéas de Carvalho Aguiar, 255, $3^{\circ}$ andar. Cerqueira César 05403-900 - São Paulo, SP. URL: http://www.dermatousp.org.br/ 
and pseudopelade of Brocq, being responsible for the description of a sign known as Sampaio sign, that represents activity of the pseudopelade.

Prof. Sampaio had an intense participation in the Brazilian Society of Dermatology and International Committee of Dermatology and was responsible for the introduction of new techniques in Brazilian dermatology, such as cryosurgery, immunodermatology and Mohs micrographic surgery,

In 1962 Department of Dermatology was created, with two disciplines, Dermatology and Venereology, and a third independent discipline, Leprology. However, in 1969 the University approved a new statute and the chairs of Dermatology and Topical Infectious Diseases were grouped into a new department, denominated Department of Tropical Medicine and Dermatology. In 1972 Prof. Carlos da Silva Lacaz joined the recently created department, as professor of Medical Geography. Prof. Lacaz was notable for his humanism and his enthusiasm for the Brazilian medical history, being responsible for the Historic Museum of the Faculty of Medicine.

The post-graduation course in dermatology of the University of Sao Paulo was created in 1973, postgraduating $239 \mathrm{MSc}$ and $\mathrm{PhD}$ until 2014.

In 1974, Prof. Lacaz became dean of the Faculty of Medicine and was essential during the creation of the Institute of Tropical Medicine, with notable researches on infectious diseases.

The residency program in Dermatology officially started in 1981, preparing 280 dermatologists until 2014 and remains until now the largest center of formation of dermatologists in Brazil, associating resident's training with a high quality health care for the patients.

The departments of Dermatology and Tropical Medicine were divided in 1986, leading to two separate departments, maintaining Prof. Sampaio as the chair of the Department of Dermatology until his retirement in 1989, when Prof. Evandro Ararigbóia Rivitti was nominated the new chairman of the Department of Dermatology and responsible for the Dermatology Division of Hospital das Clínicas until his retirement in 2010.

Prof. Rivitti developed highly relevant studies, publishing more than 150 articles, with a main interest in bullous diseases, being one of the most remarkable members of the Cooperative Group on Fogo Selvagem Research, along with Dr. Luiz A. Díaz.

The Laboratory of Medical Investigation 56 (LIM56), an important center of medical research was transferred from the Internal Medicine Department in 1999 to the Dermatology Department. In the last 5 years, around 300 papers were published in indexed journals.

Prof. Luiz Carlos Cucé was nominated co-chairman of the Department along with Prof. Rivitti from 2005 to 2006, being known for his contributions on fungal diseases and later on cosmetic dermatology.

From 2007 to 2008 Prof. José Eduardo Costa Martins was the co-chairman of the Department, developing important researches on Photobiology, Phototherapy and Mycology.

In 2010, after the retirement of Prof. Rivitti, Prof. Cyro Festa Neto was nominated the chairman of the Department of Dermatology and responsible for the Dermatology Division of Hospital das Clínicas. Prof. Festa develops significant researches on oncologic immunology and genetics, skin cancer treatment with topical immunomodulatory drugs and teledermatology.

In 2012, Prof. José Antonio Sanches Jr. was nominated full professor and, in 2014, chairman of the Department of Dermatology and coordinator of the Graduate "sensu stricto" program in Dermatology (Master and Doctorate).. Prof. Sanches is radiation oncologist and dermatologist, and has large experience on cutaneous oncology, especially in cutaneous lymphoma, related disorders and paraneoplasias. 